\title{
Real Estate Project Financial Evaluation Based on Cash Flow Estimation
}

\author{
Li Wei ${ }^{1, *}$ and Teng Yun ${ }^{2}$ \\ ${ }^{I}$ Dalian Maritime University, Liaoning Dalian 116025, China; ${ }^{2}$ Dalian Commodity Exchange, Trading Department, \\ Dalian, 116023, China
}

\begin{abstract}
This paper analyzes the factors influencing cash flows and divides them as certainty factors and uncertainty factors; it mainly discusses the uncertainty factors causing change of cash flow. For the characteristics of uncertainty of cash flows in real estate project, we adopted probability theory and mathematical statistics to balance and estimate the cash flows. Then the computer simulation method for uncertainty factors based on Beta distribution and normal distribution is proposed, with the prediction method of cash inflow and outflow. Illustrated by the case of actual real estate projects, we provided financial evaluation by traditional evaluation methods and simulation methods of uncertainty factors and compared the evaluation results. The experiment results show that the improved method has more scientific and accurate performance in basic data, compared to the traditional method, and it can acquire more reliable Evaluation results.
\end{abstract}

Keywords: Beta distribution, cash flow, estimation, financial evaluation, real estate.

\section{INTRODUCTION}

Since real estate development has a high profit margin and rate of return, it is one of the highly paid industries. However, it also has disadvantages such as large investment, long construction cycle, etc. It is easily influenced by many factors such as domestic and foreign economy, political situation, macro-control policies, so it also has a great risk. In order to ensure the investment benefit, real estate developers must make effort to avoid risks. In order to avoid risk to the maximum extent, we must perform feasibility research before project investment decision [1-3]. By investigating and analyzing related aspects affecting the research, feasibility research evaluates advancement, rationality, economy and feasibility among other aspects. The core of feasibility study is the financial evaluation. The investors make decisions whether to invest or not, according to its evaluation results.

For constant adjustment measures appearing rapidly and serious market competition environment in real estate industry, the developers will confront more uncertain factors on activities of development and investment than before. If the developers want to get success of each project, they must stress on the feasibility study with reference to the project investment decision and strengthen uncertain analysis of research in this study. Because the future change of various economic elements may bring uncertainty, it lacks enough information and advantage of prediction method. So the evaluation indicators of economic effect in investment project often predict uncertainty [4]. The direct result of uncertainty is the deviation from the evaluation value to the practical value in economic effect of investment project. It further causes more investment risks for investors and even makes decision mistakes $[5,6]$. Therefore, in order to improve the evaluation reliability of economic effect in this

*Address correspondence to this author at the Dalian Maritime University; Liaoning Dalian 116025, China; Tel: 13332267609;

E-mail: 13332267609@189.cn project and scientific decision, it needs to further analyze the influence and the degree of various external conditions, such as factor change or predictive data error on evaluation indicators of economic effect in this project, based on certainty evaluation of economic effect. Meanwhile, it also needs to determine the ability of project to bear the changes of various uncertain factors and provides a reliable decision basis for decision-makers.

This paper studies the management of cash flow in cash flow estimation of real estate project and developing cash flow control in each stage. Based on cash flow estimation management in real estate project, cash flow scale is taken as the mainline to analyze uncertain factors influencing cash flow. For minimizing the disadvantages of traditionally financial evaluation methods, computer simulation methods such as sample information of uncertain factors in Beta distribution, normal distribution, triangle distribution and uniform distribution are proposed. On this basis, this paper also studies the prediction method of cash inflow and cash outflow in financial evaluation. Finally, traditionally financial evaluation method and computer simulation method of uncertain factors are respectively applied to evaluate practical cases and perform comparative analysis of evaluation results.

\section{ESTIMATION MODEL OF CASH FLOW IN REAL ESTATE PROJECT}

Influencing factors of cash flow in real estate project are divided into certain factors and uncertain factors [7]. From the analysis of influencing factors of cash inflow, we can discover that sale price and sale area directly influence the quantity of cash inflow. If the location district of real estate project or project positioning is different, its sale price will make a great difference. The sale area will change with the prosperity degree, economic environment and policy environment in the market. Therefore, it needs reasonable estimation of sale price and sale g area. At present, cash flow estimation method in a real estate project is mainly the combination of subjective judgment prediction and mathematical 
method. Prior information of cash flow in a project is provided by decision makers according to market prediction and experience accumulation. Then, the prior information will be modified according to further collected information using various mathematical methods to reach a decision. Therefore, collecting cash flow information is the prior condition of cash flow estimation.

\subsection{Distribution Types of Cash Flow}

By investigation and research, the cash flow in real estate project has four probability distribution models as candidate models. They are: uniform distribution, normal distribution, Beta distribution and triangle distribution [8]. We adopted Anderson-Daring statistic, Kolmogorov-Smirnov statistics, and Chi-Square statistics [9-11] for testing and selecting the optimal probability distribution model. The discriminating standard of the optimal probability distribution type is: if test results of AD statistics, KS statistics and Chi-square statistics are the same, this result will be determined as the standard. If test results of these three statistics are different, due to the stability of $\mathrm{AD}$ statistics, the test result of $\mathrm{AD}$ statistics will be set as standard. Taking selling price as an example to collect price data of similar projects in real estate project, the acquired results are shown in Table $\mathbf{1}$.

Fitting software of probability distribution is applied for optimization of fitting probability distribution to cash flow in a real estate project. The test results of $\mathrm{AD}$ statistics, KS statistics and Kapha's statistics prove that the sale price obeys normal distribution. Similarly, the sale area can be determined to follow Beta distribution. Factors such as construction and installation expense, construction expense of infrastructure, management expense, reserve funds, sale cost, sales tax and the plus, land tax, income tax, cash inflow, cash outflow and net cash flow all obey normal distribution.

\subsection{Principle of Cash Flow Estimation Model}

Since cash flow of a real estate project has many uncertain factors, so it cannot be considered as a determinant data. Uncertain estimation of cash flow model in real estate project is implementing probability theory and mathematical statistics to balance and predict the cash flow under error condition. Based on the analysis of the above, the distribution types of cash flow, which need to be estimated are Beta distribution and normal distribution [12]. Based on the difference of estimated content distribution types, the cash flow estimation can be divided into cash flow estimation obeying Beta distribution and cash flow estimation obeying normal distribution. Illustrated by the former we provide the estimation method as follows:
The cash flow obeying Beta distribution can generally estimate the most optimistic value $\alpha$, most possible value $m$ and most pessimistic value $b$. When these parameters are estimated, we can acquire the expectation $\mu$ and corresponding variance $\sigma^{2}$. The computation equations are:

$\mu=\frac{a+4 m+b}{6}$

$\sigma^{2}=\left(\frac{b-a}{6}\right)^{2}$

According to the characteristics of mathematical expectation and variance, the expectation $T E_{k}$ and variance $E$ are:

$$
\begin{aligned}
& T E_{k}=\mu=\sum_{i=1}^{k}\left(\frac{a_{i}+4 m_{i}+b}{6}\right) \\
& E=\sigma^{2}=\sum_{i=1}^{k}\left(\frac{b_{i}-a_{i}}{6}\right)^{2}
\end{aligned}
$$

$k$ is the number of activities in this equation. Based on Lindeberg's theorem, when the activity number is enough, the total activity approximately obeys normal distribution and its probability density function is:

$$
f(T)=\frac{1}{\sqrt{2 \pi \sigma}} e^{-\frac{\left(T-T E_{k}\right)^{2}}{2 \sigma^{2}}}
$$

Generally, the probability less than or equal to the given cash can be solved by its normal distribution function [13]:

$$
P\left(T \leq T E_{k}\right)=\int_{-\infty}^{T_{r}} \frac{1}{\sqrt{2 \pi \sigma}} e^{-\frac{\left(T-T E_{k}\right)^{2}}{2 \sigma^{2}}} d T
$$

$T_{r}$ is given estimation value of cash flow items.

If the arriving probability is known, we can get wanted cash flow $T$ by checking $Z$ value corresponding to the probability in normal distribution table, and equation 4 :

$T=T E_{k}+Z \sigma$

\section{CASH PREDICTION OF REAL ESTATE PRO- JECTS FINANCIAL EVALUATION}

\subsection{Cash Inflow Prediction}

Cash inflow is composed of sales income and rental income, denoted respectively as $y_{1}$ and $y_{2}$ 。 The sales prices

\begin{tabular}{|c|c|c|c|c|c|c|c|}
\hline & Distribution & \multicolumn{2}{|c|}{ Kolmogorov Smirnov } & \multicolumn{2}{|c|}{ Anderson Daring } & \multicolumn{2}{|c|}{ Chi-Squared } \\
\hline 1 & Beta & 0.18995 & 4 & 2.9372 & 2 & 2.7505 & 3 \\
\hline 2 & Normal & 0.15883 & 1 & 0.71166 & 1 & 0.5079 & 1 \\
\hline 3 & Triangular & 0.16147 & 2 & 3.72491 & 3 & 1.3077 & 2 \\
\hline
\end{tabular}
and rental prices are uncertain factors. Therefore, the procedures of cash inflow prediction are described as follows.

Table 1. Sales price distribution type. 
According to the simulation methods of uncertainties, and the expectation and standard deviations of sales price and rental price, denoted as $a_{1}, u_{1}$ and $a_{2}, u_{2}$ respectively; the sale price of residential buildings is $P_{1}=a_{1} \pm u_{1}$; rental price is $P_{2}=a_{2} \pm u_{2}$.

If the sales area of project is $S_{1}$, its sales income $y_{1}$ is:

$y_{1}=P_{1} \times s_{1}=\left(a_{1} \pm u_{1}\right) \times s_{1}=a_{1} s_{1} \pm u_{1} s_{1}$

$a_{1} s_{1}$ denotes mathematical expectation of sale income and $u_{1} s_{1}$ denotes standard deviation of sale income.

If rental area is $S_{2}$, the rental income $y_{2}$ is:

$y_{2}=P_{2} \times s_{2}=\left(a_{2} \pm u_{2}\right) \times s_{2}=a_{2} s_{2} \pm u_{2} s_{2}$

For the prediction of cash inflows, from probability theory [14] we know: when variables $\mathcal{E}$ and $\eta$ are independent, the expectation and variance of the variables have the following characteristics:

$\left\{\begin{array}{l}E(\varepsilon \pm \eta)=E \varepsilon \pm E \eta \\ \sigma^{2}(\varepsilon \pm \eta)=\sigma^{2}(\varepsilon)+\sigma^{2}(\eta)\end{array}\right.$

Therefore, if we use $C I$ to denote cash inflows, its expectation $E(C I)$ and variance $\sigma^{2}(C I)$ are:

$E(C I)=E\left(y_{1}^{\prime}+y_{2}^{\prime}\right)=E\left(y_{1}^{\prime}\right)+E\left(y_{2}^{\prime}\right)=a_{1} s_{1}+a_{2} s_{2}$

$\sigma^{2}(C I)=\sigma^{2}\left(y_{1}^{\prime}+y_{2}^{\prime}\right)=\sigma^{2}\left(y_{1}^{\prime}\right)+\sigma^{2}\left(y_{2}^{\prime}\right)=\left(u_{1} s_{1}\right)^{2}+\left(u_{2} s_{2}\right)^{2}$

The cash inflow is:

$C I=E(C I)+\sigma(C I)=\left(a_{2} s_{2} \pm u_{2} s_{2}\right) \pm \sqrt{\left(u_{1} s_{1}\right)^{2}+\left(u_{2} s_{2}\right)^{2}}$

$\sigma(C I)$ denotes the standard deviation of cash inflow.

\subsection{Cash Outflow Prediction}

Cash outflow is constituted by certainty factors which are preliminary engineering cost, construction project installation cost, urban construction cost, public matching facilities construction cost, financial cost, and other cost; and "derivation" uncertain factors which are management cost, sales cost, reserve cost, sales tax and additional, land value-added tax, income tax, land cost, and infrastructure construction cost. Its prediction steps are:

\section{(1) Certainty factors cost estimation}

According to traditional estimation methods of certainty factors, we estimated the preliminary engineering cost, construction installation cost, urban construction cost, public matching facilities construction cost, financial cost, and other cost successively. They are respectively denoted as $y_{1}, y_{2}, y_{3}, y_{4}, y_{5}, y_{6}$.

(2) Computer simulation of uncertainty factors price

The expectation and standard deviation of land price are simulated with $a_{3}$ and $u_{3}$ so that the land price is $P_{3}=a_{3} \pm u_{3}$.

Similarly, we can simulate the expectation and standard deviation of unilateral price of infrastructure costs, with $a_{4}$ and $u_{4}$. Then, the unilateral price is $P_{4}=a_{4} \pm u_{4}$.

(3) Determination of uncertainty factors' expense
If the site area of project is $S_{3}$ and land price is $y_{7}$, then

$y_{7}=P_{3} \times s_{3}=\left(a_{3} \pm u_{3}\right) \times s_{3}=a_{3} s_{3} \pm u_{3} s_{3}$

If the building area of the project is $S_{4}$ and infrastructure expense is $y_{8}$, then

$y_{8}=P_{4} \times s_{4}=\left(a_{4} \pm u_{4}\right) \times s_{4}=a_{4} s_{4} \pm u_{4} s_{4}$

The expense of management, contingencies, sales, sales taxes and surcharges, land tax and income tax are denoted respectively as $y_{9}, y_{10}, y_{11}, y_{12}, y_{13}, y_{14}$. The expense proportions are denoted as $i_{1}, i_{2}, i_{3}, i_{4}, i_{5}, i_{6}$. The sum of expense of land, preliminary engineering, construction and installation, urban construction, infrastructure and public facilities construction is denoted as $y_{0}$. Then, according to the expense determined by above factors, the difference between total profit and the amount of deductions can be calculated, as denoted by $y_{15}$ and $y_{16}$. So,

$$
\left\{\begin{array}{l}
y_{9}=y_{0} i_{1}=a_{5} \pm u_{5} \\
y_{10}=y_{0} i_{2}=a_{6} \pm u_{6} \\
y_{11}=y_{0}^{\prime} i_{3}=a_{7} \pm u_{7} \\
y_{12}=y_{0}^{\prime} i_{4}=a_{8} \pm u_{8} \\
y_{13}=y_{15} i_{5}=a_{9} \pm u_{9} \\
y_{14}=y_{16} i_{6}=a_{10} \pm u_{10}
\end{array}\right.
$$

(4) The prediction of cash outflow.

We use $C O$ to denote the cash outflow. Then, its expectation $E(C O)$ and variance $\sigma^{2}(C O)$ are:

$$
\begin{aligned}
E(C O) & =E\left(y_{1}+y_{2}+\ldots+y_{14}\right)=E\left(y_{1}\right)+E\left(y_{2}\right)+\ldots+E\left(y_{14}\right) \\
& =y_{1}+y_{2}+\ldots+y_{6}+a_{3} s_{3}+a_{4} s_{4}+a_{5}+a_{6}+\ldots+a_{10} \\
\sigma^{2}(C O) & =\sigma^{2}\left(y_{1}+y_{2}+\ldots+y_{14}\right)=\sigma^{2}\left(y_{1}\right)+\sigma^{2}\left(y_{2}\right)+\ldots+\sigma^{2}\left(y_{14}\right) \\
& =\left(u_{3} s_{3}\right)^{2}+\left(u_{4} s_{4}\right)^{2}+u_{5}^{2}+u_{6}^{2}+\ldots+u_{10}^{2}
\end{aligned}
$$

The cash outflow is:

$$
\begin{aligned}
C O= & E(C O)+\sigma(C O)=\left(y_{1}+y_{2}+\ldots+y_{6}+a_{3} s_{3}+a_{4} s_{4}+a_{5}+a_{6}+\ldots+a_{10}\right) \\
& \pm \sqrt{\left(u_{3} s_{3}\right)^{2}+\left(u_{4} s_{4}\right)^{2}+u_{5}^{2}+u_{6}^{2}+\ldots+u_{10}^{2}}
\end{aligned}
$$

Then, the net cash flow is:

$$
\begin{aligned}
C I-C O & =E(C I-C O) \pm \sigma(C I-C O) \\
& =\left(a_{1} s_{1}+a_{2} s_{2}-y_{1}-y_{2}-\ldots-y_{6}-a_{3} s_{3}-a_{4} s_{4}-a_{5}-a_{6}-\ldots-a_{10}\right) \\
& \pm \sqrt{\left(u_{3} s_{3}\right)^{2}+\left(u_{4} s_{4}\right)^{2}+u_{5}^{2}+u_{6}^{2}+\ldots+u_{10}^{2}}
\end{aligned}
$$

\section{CASE STUDY OF FINANCIAL EVALUATION}

The project case is a real estate phase II project which is mainly composed of small high-rise and multilayer houses. It totally invests about 76.05 million yuan. The land area is $101.03 \mathrm{mu}$. The building area is $39,770.62$ square meters, including residence area of 32174.9 square meters, business building area of 1230 square meters, and garages and other building area of 6365.72 square meters. This phase of the project consists of five buildings. Building 1, Building 2, Building 3 have 7 floors; Building 4 has 6 floors; and Building 5 has 12 floors. The house types mainly include two bedrooms and two parlors apartment; three bedrooms and three parlors apartment; four bedrooms and three parlors apart- 
ment, duplex apartment, etc. The house area range from 85240 square meters, and the 120 square meters house area is the majority house type. The project used its own fund to pay off the land cost and preliminary engineering costs. The project started in October 2011. The completion and acceptance date was around November 2012. The project started advanced sale in January 2013. The main economic and technical indicators are shown in Table 2:

Table 2. Main economic and technical indicators of project.

\begin{tabular}{|c|c|c|}
\hline Items & Unit & Number \\
\hline \hline Site area & $\mathrm{mu}$ & 101.03 \\
\hline Total building area & $m^{2}$ & 39770.62 \\
\hline Public building area & $m^{2}$ & 4500 \\
\hline Residential floor area & $m^{2}$ & 32174.9 \\
\hline Salable area & $m^{2}$ & 1230 \\
\hline Households living & household & 1135 \\
\hline Green area & $m^{2}$ & 2653.8 \\
\hline Basement & $m^{2}$ & 6365.72 \\
\hline
\end{tabular}

\subsection{Uncertainties in Computer Simulation of Beta Dis- tribution}

The development cycle obeys Beta distribution and the computer simulation process is described as follows:

(1) Information collection of development cycle

This paper invites five experts to estimate the development cycle of project. The information collection data is shown in Table 3:

Table 3. Information collection data.

\begin{tabular}{|c|c|c|c|c|c|}
\hline \multirow{2}{*}{ Types } & \multicolumn{5}{|c|}{ Predicted value of experts } \\
\cline { 2 - 6 } & $\mathbf{1}$ & $\mathbf{2}$ & $\mathbf{3}$ & $\mathbf{4}$ & $\mathbf{5}$ \\
\hline \hline$b$ & 30 & 35 & 31 & 28 & 30 \\
\hline$m$ & 33 & 35 & 36 & 32 & 37 \\
\hline$a$ & 35 & 38 & 39 & 34 & 42 \\
\hline
\end{tabular}

(2) One-dimensional information diffusion

The samples set of the most optimal estimation $b$ is $\left\{\begin{array}{lllll}30 & 32 & 31 & 28 & 30\end{array}\right\}$. Its diffusion parameter is: $h=0.8146 \times(32-28)=3.2584$. The diffusion range is:

$$
\omega_{\max }=30.2+3 \times 1.3266=34.1799
$$

$\omega_{\min }=30.2-3 \times 1.3266=26.2201$

The diffusion step is:

$$
\Delta=\min \{30.2-29.3,31.5-30.2,1\}
$$

So, the weighted average of $b$ after diffusion is 30.3627 .
Similarly, we can get the diffusion function and parameters of the most possible accurate estimation, and the weighted average of the most pessimistic value $\alpha$ : $\bar{m}=34.8017$ and $\bar{a}=37.5323$.

\section{(3) Computer simulation of development cycle}

According to the above derivation, we have $r=3.2691$ and $s=4.5038$. First, we made simulation for 5 times, that is, $N_{0}=5$. For the given $\beta=0.95, \delta=0.01$, we get $N=20000$.

\subsection{Cash Flow Prediction}

\section{(1) Sales estimation}

The project started sales since January 2013. The experts calculated the project annual estimation sales in 2013. According to experts' estimation, sales of the project are simulated for each month. Similarly, we can find what the other month's sales area simulation values in 2013 were. It is known that monthly sales volume obeys Beta distribution, and the total sale is equal to the sum of monthly sales. Based on Lindeberg's theorem, the total sale is found to obey normal distribution. By simulation, we know that the annual sales area is 146,211 square meters under the probability of 0.9 . The sales period of project is from 2013 to 2015, when $n=3$. Similarly, we can estimate each year's expectation, standard deviation and sales area under probability of 0.9 during 2014 and 2015. According to the computation, we can get the expectation of the project's total sales, which is 344,050 , and the standard deviation is 6930. The total sales volume of the project is simulated and the results are shown in Fig. (1).

The simulation shows a value of total sales expectation during sales period to be $344085 \mathrm{~m}^{2}$. The simulation value of standard deviation is 6918 . Under the probability of 0.9 , the total sales area of the project is $352957 \mathrm{~m}^{2}$.

\section{(2) Evaluation of cash inflow}

For cash inflow, the times of simulation is 20000 , so the simulation results are given in Fig. (2). As is known from the result, the cash inflow under the probability of 0.9 is 2458771684 .

\section{(3) Evaluation of cash outflow}

As illustrated by the case of infrastructure investment and construction, the total construction investment is estimated. Based on the information about the expense of infrastructure of the similar projects, we could compute the expected infrastructure construction expense of unit area to be $206 \mathrm{yu}-$ $\mathrm{an} / \mathrm{m}^{2}$, and the standard deviation to be 5 . For infrastructure construction expense, the simulation results are shown in Fig. (3).

Based on the results, we could deduce the expected total infrastructure construction expense of the project to be 411795 yuan, and the standard variance to be 9996 . Then, the infrastructure construction expense under the probability of 0.9 is 424589 yuan.

Similarly, we can get the expense of management, sales cost, reserve cost when the probability is $90 \%$. Besides construction project installation cost, other cost such as: except construction and installation costs, infrastructure costs, 


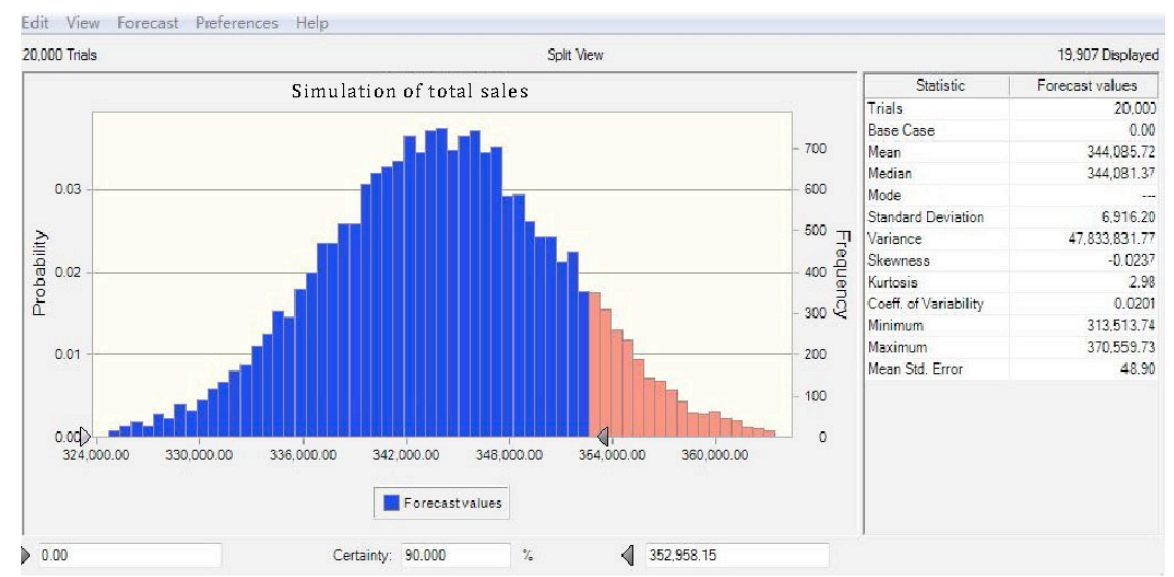

Fig. (1). Simulation graph of total sales.

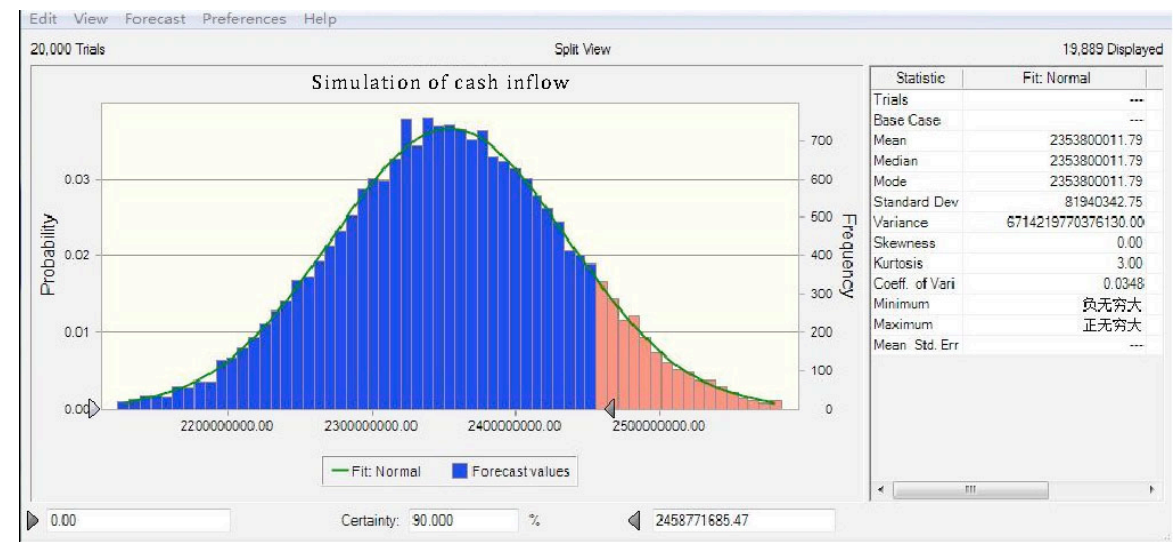

Fig. (2). Simulation graph of cash inflow.

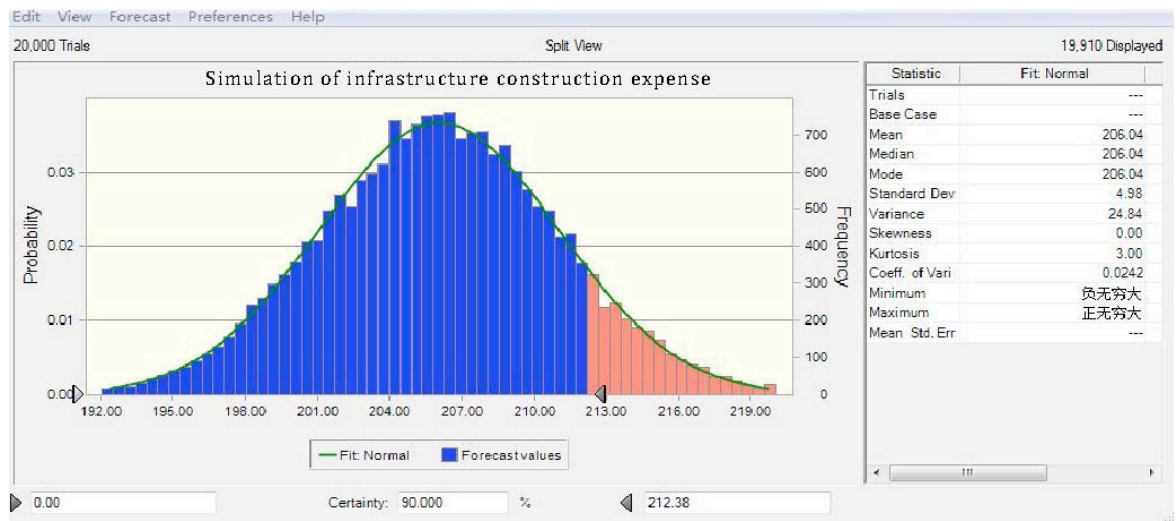

Fig. (3). Simulation graph of infrastructure construction expense.

management cost, reserve cost, sales cost, the sum of land cost, preliminary engineering cost, public matching facilities cost, financial cost, etc. incurred 696,110,194 yuan in this project. Based on the computation result, the expectation of management cost is 47.29 million yuan, and the standard deviation is 210000 yuan; the expectation of reserve cost is 47.07 million yuan and the standard deviation is $230000 \mathrm{yu}-$ an; and the expectation of sales cost is 63.4 million yuan and the standard deviation is 1.1 million yuan. For construction investment, the simulation results are shown in Fig. (4).

From the simulation it is known that the construction investment under the probability of 0.9 is 1537974962 yuan.

\subsection{Comparison of Financial Evaluation Results}

While making project financial evaluations, the difference between the improved method and traditional methods has to be realized. The comparative analysis of evaluation indicators is given in Table 4 . It can be seen that, when determining data on the basis of financial evaluation, the scheme in this paper considers uncertainty factors influencing cash flow adequately. Namely, as we scientifically collected the original data of uncertainty factors, improved information diffusion method was used to deal with the original data of uncertainty factors. Then, these data were simulated using computer simulation software. This new 


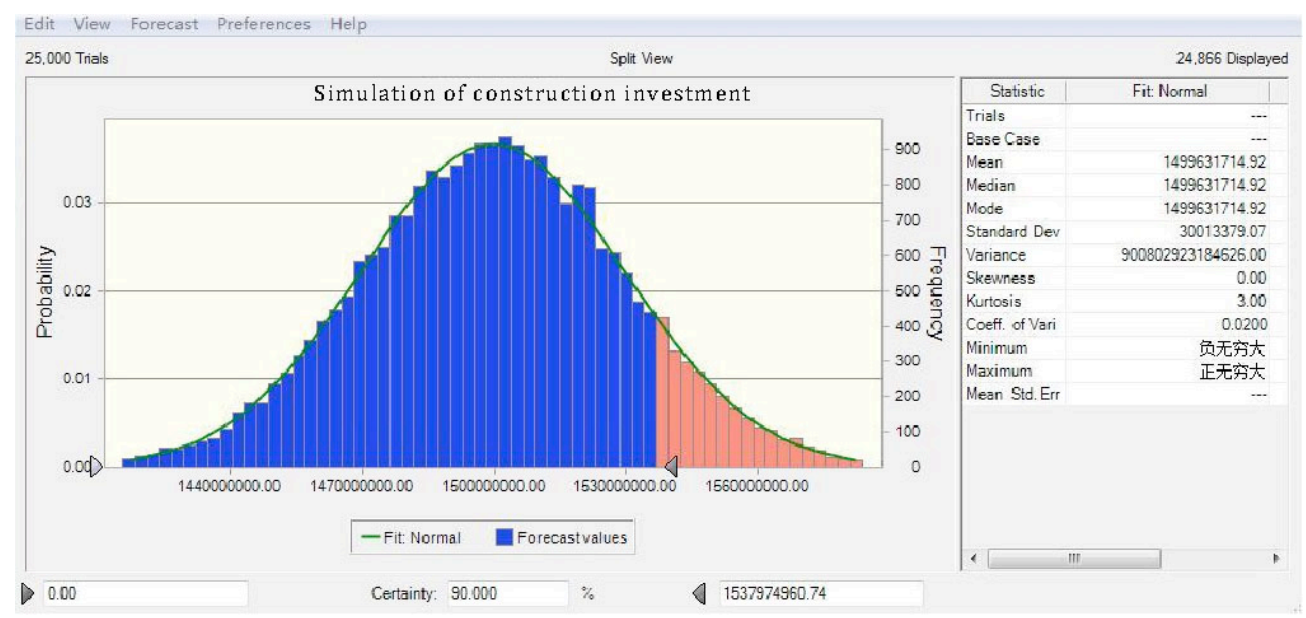

Fig. (4). Simulation graph of construction investment.

Table 4. Financial evaluation indicators comparison.

\begin{tabular}{|c|c|c|c|c|}
\hline \multirow{2}{*}{ Evaluation indicators } & \multicolumn{3}{|c|}{ Prediction method } \\
\cline { 2 - 5 } & \multicolumn{2}{|c|}{ Traditional method } & After-tax & \multicolumn{2}{c|}{ Improved method } \\
\cline { 2 - 5 } & Pre-tax & 7.676 million yuan & $(20.522 \pm 0.548)$ million yuan & $(8.57 \pm 0.672)$ million yuan \\
\hline \hline FNPW & 18.7961 million yuan & $18.75 \%$ & $31.11 \% \pm 0.33 \%$ & $19.33 \% \pm 0.65 \%$ \\
\hline FIRR & $30.02 \%$ & 3.65 years & $(3.27 \pm 0.01)$ years & $(3.62 \pm 0.02)$ years \\
\hline$P_{1}$ & 3.3 years & 4.11 years & $(3.61 \pm 0.01)$ years & $(4.12 \pm 0.08)$ years \\
\hline$P_{1}^{\prime}$ & 3.65 years & & & \\
\hline
\end{tabular}

method overcomes the disadvantages of not considering the effects of uncertainty factors and low precision of financial evaluation caused by original data used in the traditional financial evaluation. It improves the reliability of financial evaluation results effectively, and provides scientific basis of a decision for the investment decision-makers.

\section{CONCLUSION}

The uncertain factors of cash inflow and cash outflow influencing the real estate projects are, important factors which influence the accuracy of financial estimation in such projects. This paper analyzed and simulated the uncertain factors influencing cash flow to obtain data based on the financial evaluation, to obtain a more scientific and objective financial evaluation results. In the case study, this paper respectively performs financial evaluation of actual projects based on both the traditional financial evaluation method and the improved method with uncertain factors simulation. The results show that our new method is more scientific and accurate than traditional methods in determining the basis data. Therefore, we can get more reliable financial evaluation results, which can provide a reliable and scientific basis of a decision for decision-makers of real estate projects.

\section{CONFLICT OF INTEREST}

The authors confirm that this article content has no conflict of interest.

\section{ACKNOWLEDGEMENTS}

This work is supported by the Fundamental Research Funds for the Central Universities (3132015056).

\section{REFERENCES}

[1] H. Koyama, N. Yoshida, and K. Amasaka, "The A-MPM decisionmaking model for film project investment: A partnership with filmmakers", In: Proceedings of International conference on System Science and Simulation in Engineering, Iwate, Japan, pp. 215220, 2010.

[2] Z. Yongfei, and C. Li, "Decision model of the best investment opportunity in coal mine project based on real option", Telkomnika - Indonesian Journal of Electrical Engineering, vol. 11, no. 7, pp. 4048-4053, 2013.

[3] H. Smyth, and L. Laurence, "Differences in decision-making criteria towards the return on marketing investment: A project business perspective", International Journal of Project Management, vol. 33, no. 1, pp. 29-40, 2015.

[4] J. Lui, D. Pan, and X. Tian, "The Risk Evaluation of Real Estate Project in the Stage of Decision", Journal of Systems \& Management, vol.16, no. 2, pp. 194-202, 2007.

[5] H. Zhao, and L. Chen, "Research on selecting public investment project based on a decision support system, Key Engineering Materials", Advanced Materials and Computer Science, vol. 474, pp. 2239-2242, 2011.

[6] M. Zeng, K. Tian, and F. Yan, "Analysis on investment decision of power generation project in electricity market considering flexible tactics", Power System Technology, vol. 34, no. 11, pp. 151-155, 2010.

[7] Y. Chen, and S. Chen, "Stress Testing on Default Probability of Real Estate Development Enterprises", Finance Forum, vol. 160, no. 4, 2009. 
[8] S. Jelena, "Real estate investment portfolio decision-making Under the risk and uncertainty", Proceedings of 10th World MultiConference on Systemics, Cybernetics and Informatics, Orlando, FL, United states, pp. 69-74, 2006.

[9] M. Wang, and P. Liu, "An extended VIKOR method for investment risk assessment of real estate based on the uncertain linguistic variables", Advances in Information Sciences and Service Sciences, vol. 3, no. 7, pp. 35-46, 2011.

[10] X. Ke, F. Diao, and K. Zhu, "A real option model suitable for real estate project investment decision", Advanced Materials Research, vol. 225-226, pp. 234-238, 2011.

[11] H. Carolyn, G. Michael, and P. S. W. Fong, "Value management for sustainable decision making", In: Proceedings of the Institution of Civil Engineers: Municipal Engineer, vol. 163, no. 1, pp. 43-50, 2010.

[12] Y. Wo, "Decision-making model on real estate investment", Mechatronics and Applied Mechanics, vol. 157-158, pp. 1230-1232, 2012.

[13] O. Liu, and Z. Liao, "Improvements in Estimating Model of Investment Cash Flow", Journal of Hubei University of Economics, vol. 7, no. 6, pp. 101-105, 2009.

[14] C. Wang, and J. Li, "Evaluation model based on fuzzy comprehensive evaluation method of the post-evaluation of real estate projects", Proceeding of International Conference on Information Management, Innovation Management and Industrial Engineering, Sanya, China, pp. 154-157, 2012.

(C) Wei and Yun; Licensee Bentham Open.

This is an open access article licensed under the terms of the (https://creativecommons.org/licenses/by/4.0/legalcode), which permits unrestricted, noncommercial use, distribution and reproduction in any medium, provided the work is properly cited. 